\title{
Unusual cause of acquired RBBB
}

Himanshu Mahla, Shivakumar Bhairappa, Sunil Kumar KR, Cholenahally Nanjappa Manjunath

Department of Cardiology, Sri Jayadeva Institute of Cardiovascular Sciences \& Research, Bangalore, Karnataka, India

\section{Correspondence to} Dr Shivakumar Bhairappa, snbhairappa@gmail.com

\section{DESCRIPTION}

A 34-year-old woman presented with a 3-day history of atypical chest pain. There were no risk factors for coronary artery disease. ECG showed right bundle branch block (RBBB) with normal sinus rhythm (figure 1). Troponin $\mathrm{T}$ test was positive according to reference laboratory standards. Echocardiogram (transthoracic) showed no regional wall motion abnormality with normal left ventricle (LV) ejection fraction (videos 1 and 2). Coronary

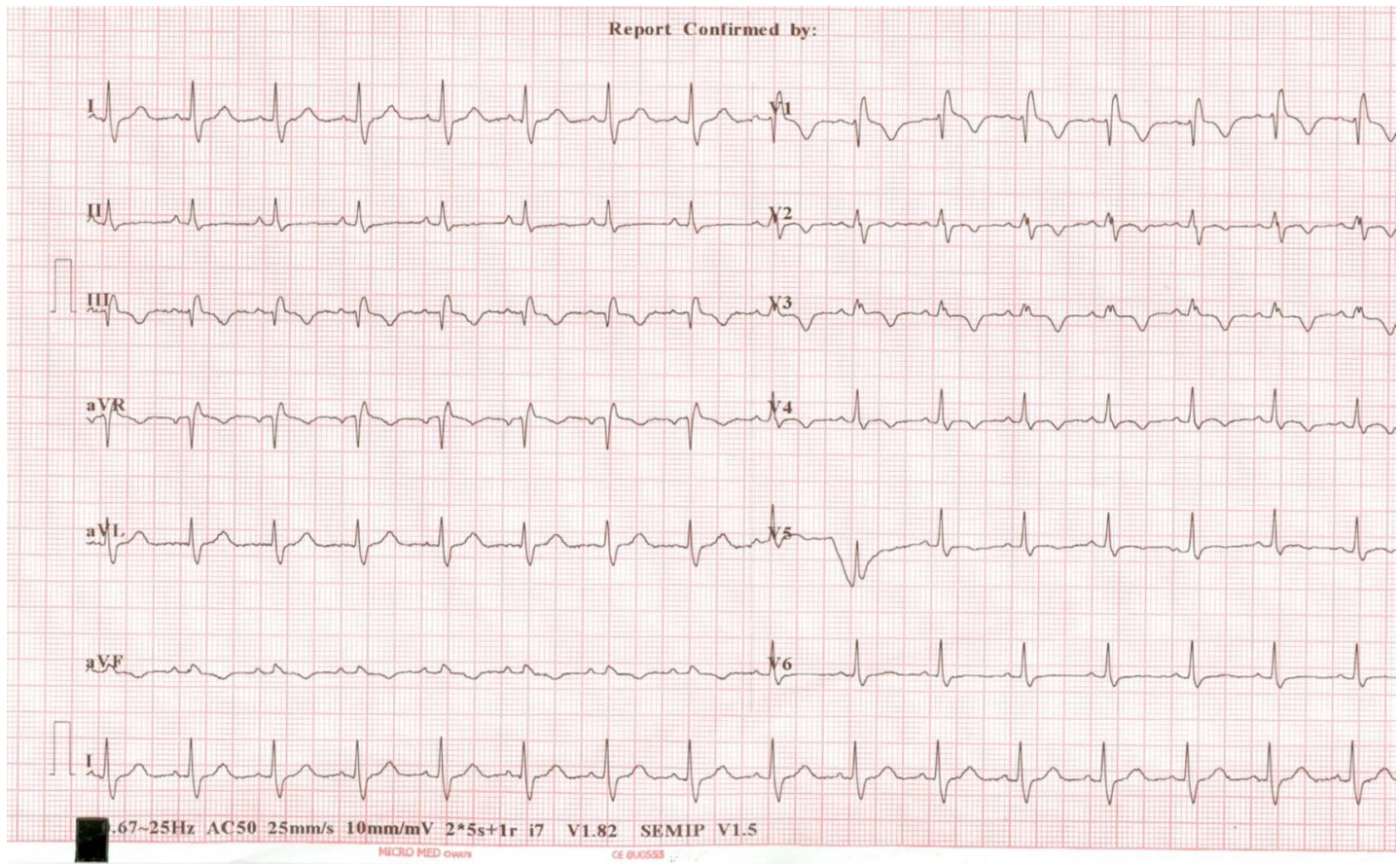

Figure 1 Twelve-lead ECG showing normal sinus rhythm with right bundle branch block.

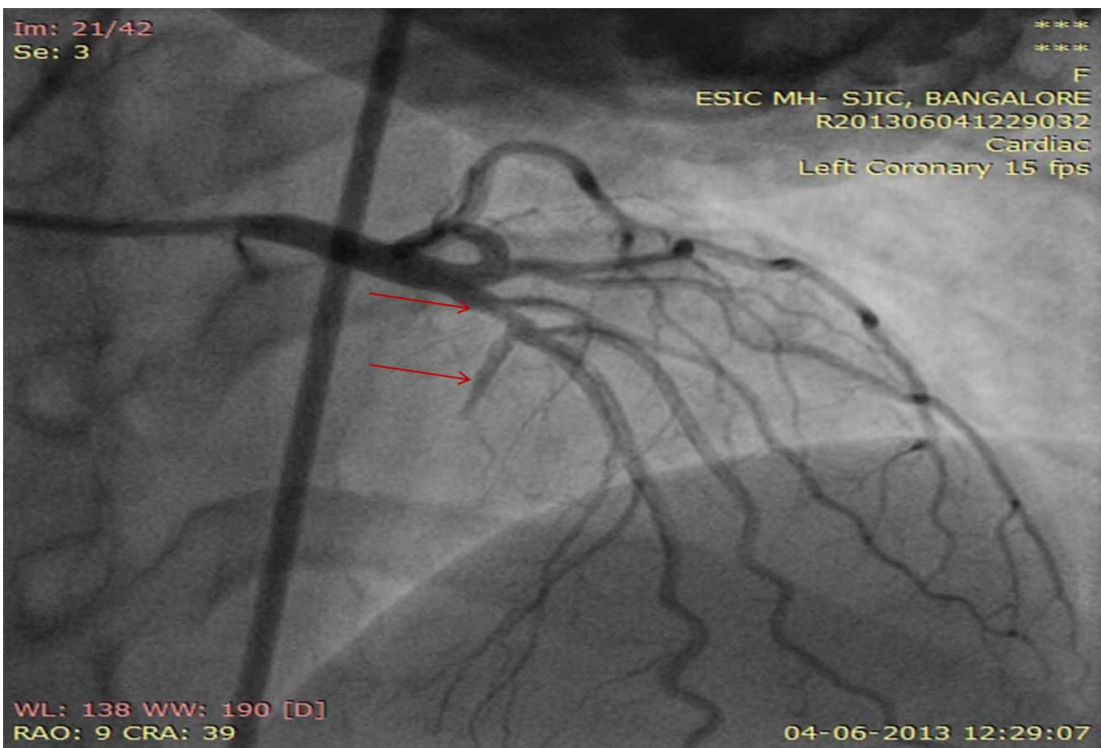

Figure 2 Right anterior oblique cranial view of the left system angiogram showing occluded septal artery with insignificant plaquing in left anterior descending. 


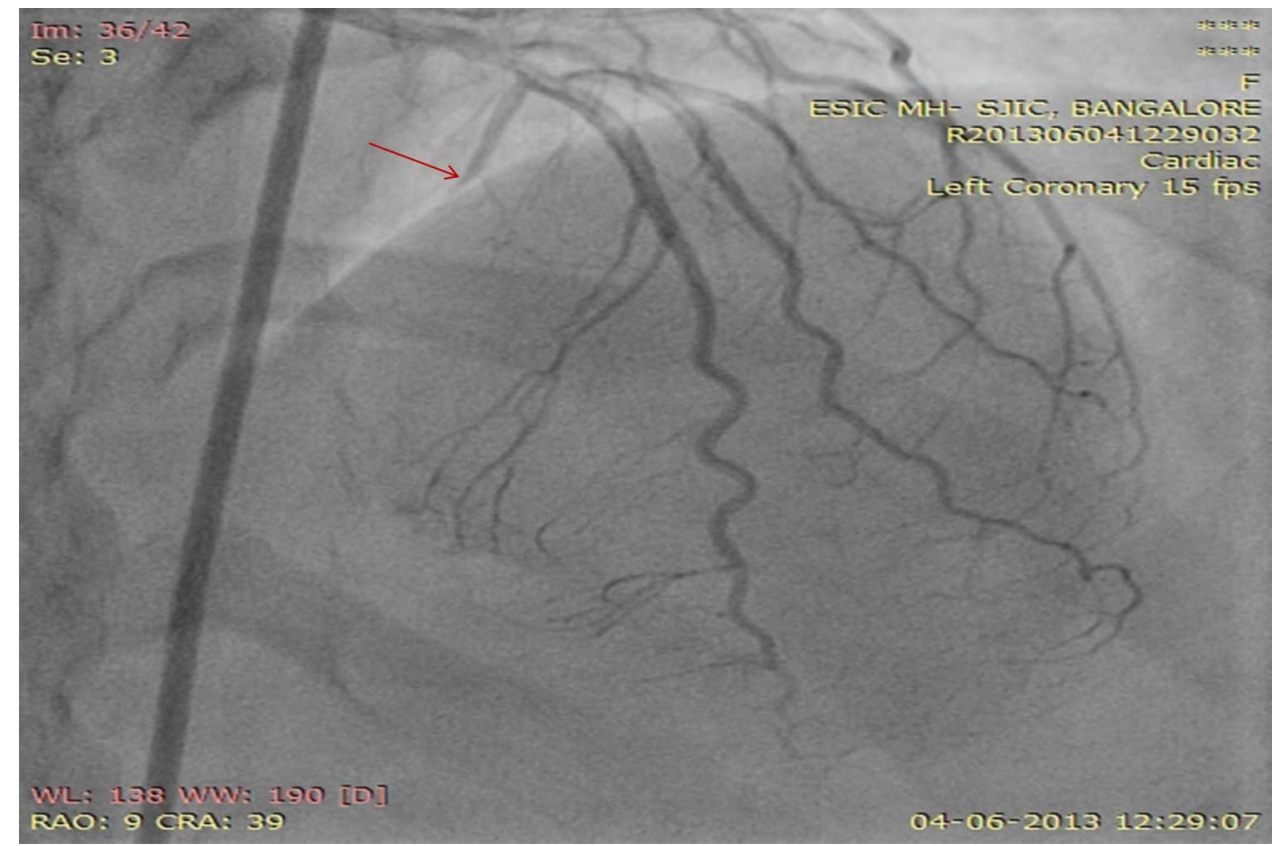

Figure 3 Right anterior oblique carnial view of the left system angiogram showing occluded septal artery with type II left anterior descending coronary artery.

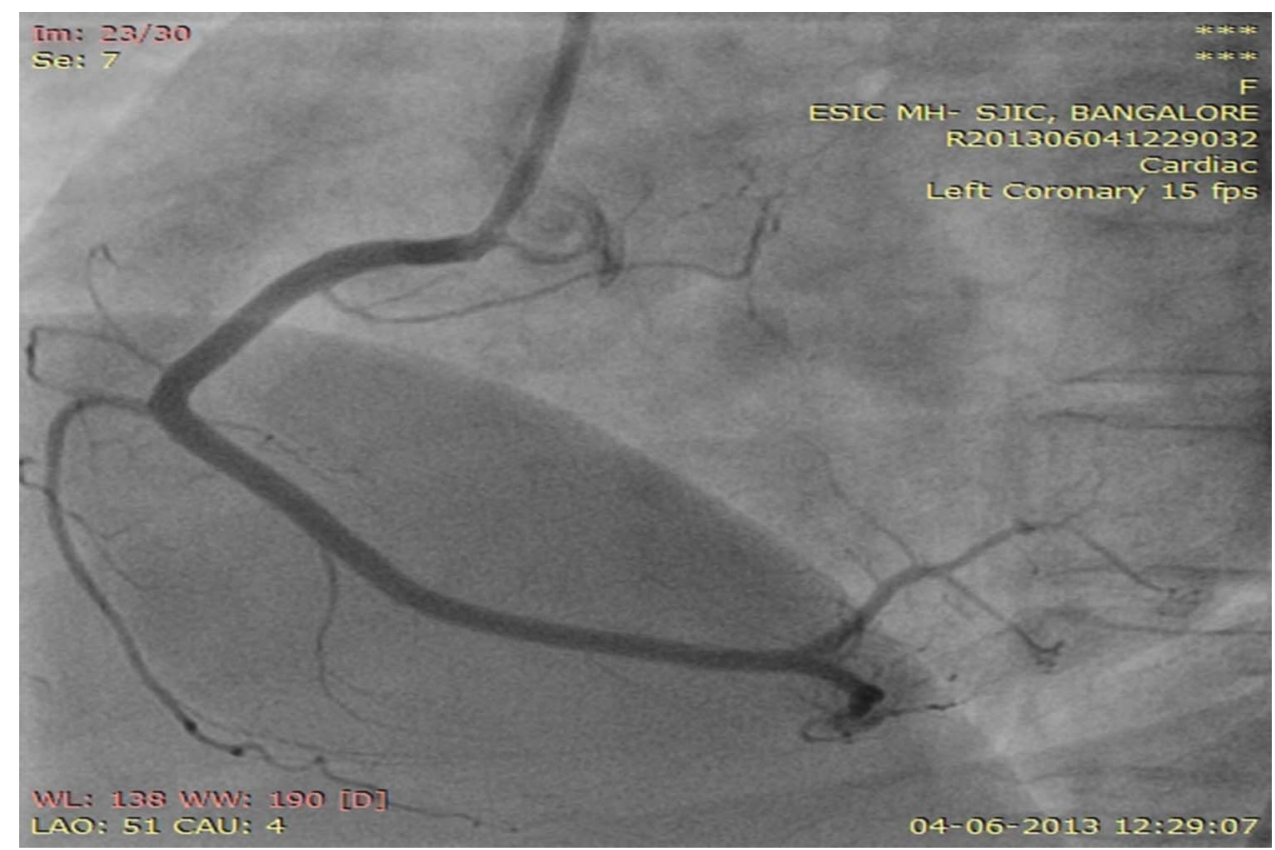

Figure 4 Left anterior oblique view of the right system angiogram showing normal dominant right coronary artery.

angiogram showed isolated occlusion of septal artery with insignificant disease in left anterior descending (LAD; figures 2 and 3 ; video 3). Left-circumflex artery and right coronary artery were normal (figure 4; videos 4 and 5).

We represent a case of isolated occlusion of septal artery manifesting as NSTEMI with RBBB on electrocardiogram. Only a few case reports are there for isolated occlusion of septal artery. ${ }^{1}{ }^{2}$ Although the existence of $\mathrm{qRBBB}$ on ECG is taken seriously by every cardiologist and physician, our case shows the importance of isolated RBBB with no 'q' waves which is generally a neglected phenomenon on ECG. Isolated RBBB on ECG can show isolated occlusion of septal artery which is rare. Septal artery occlusion can also manifest with complete heart block. ${ }^{3}$ Our patient is on optimal medical management and doing well. 


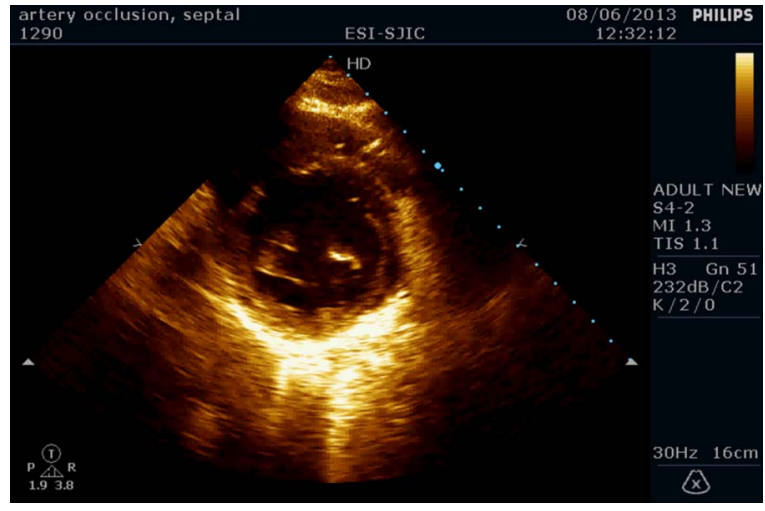

Video 1 Parasternal short axis view in transthoracic echocardiogram showing normal LV ejection fraction with no regional wall motion abnormality.

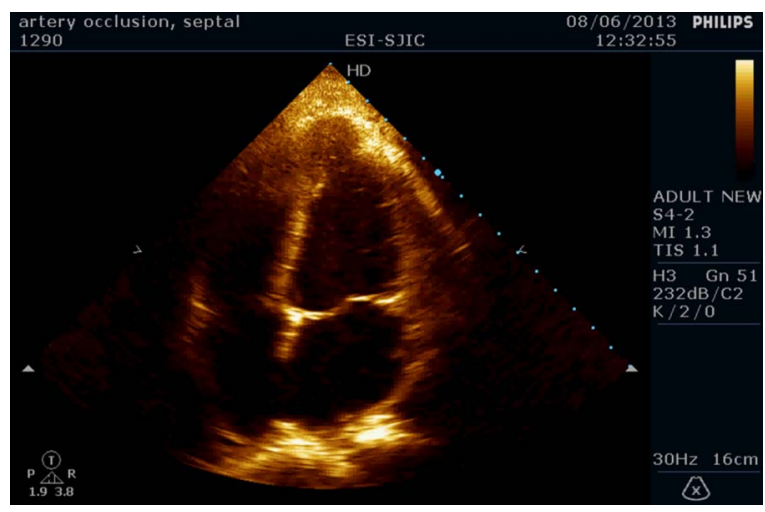

Video 2 Apical 4 chamber view in transthoracic echocardiogram showing normal LV ejection fraction with no regional wall motion abnormality.

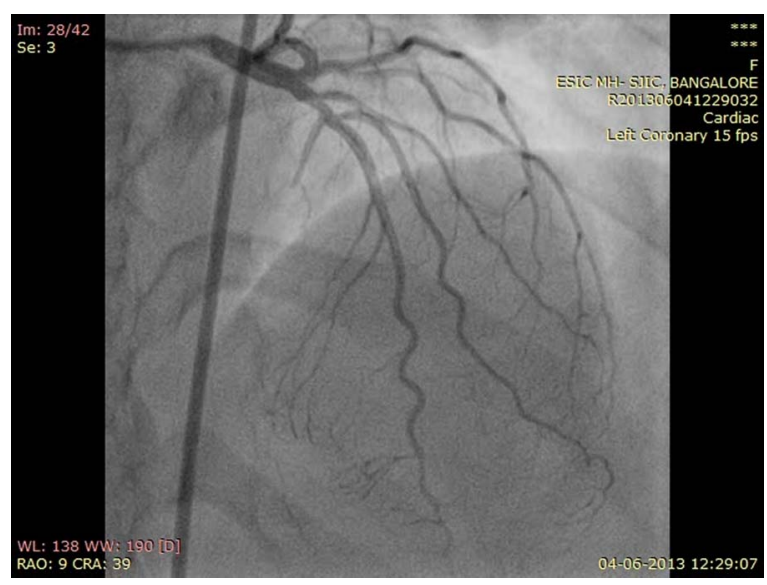

Video 3 Right anterior oblique cranial view of left system angiogram showing occluded septal artery with insignificant plaquing in LAD.

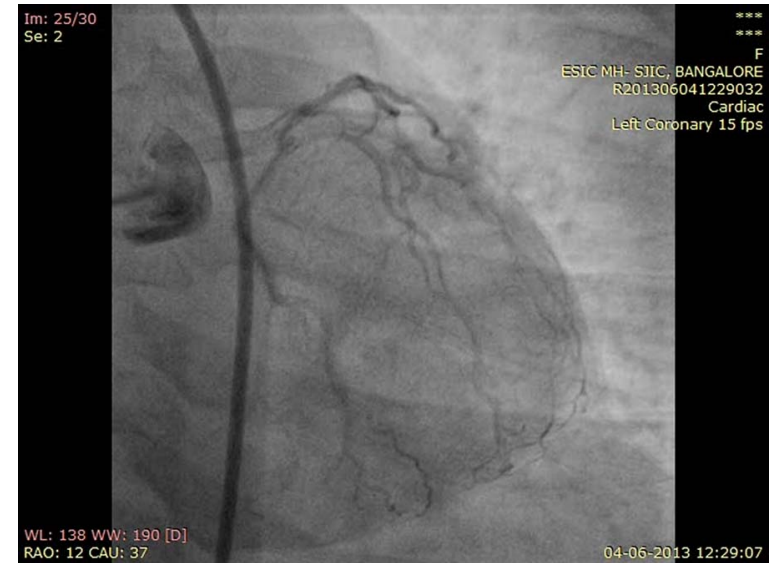

Video 4 Right anterior oblique caudal view nondominant normal LCX.

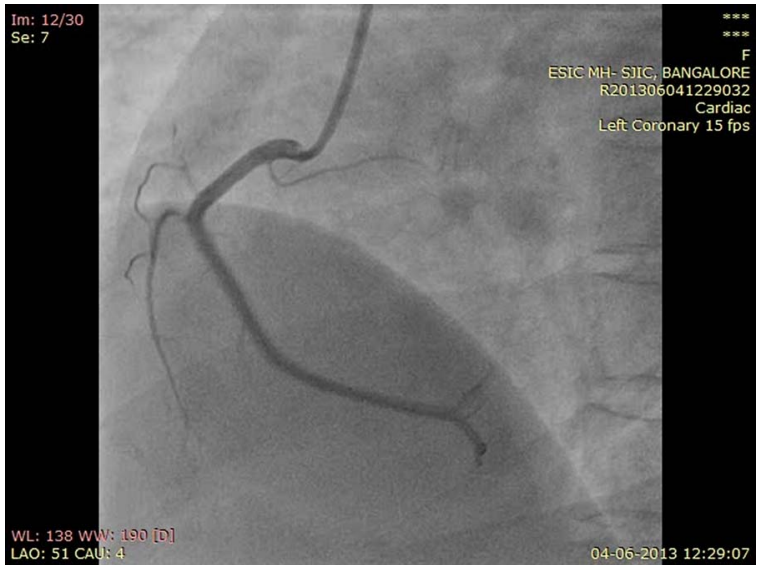

Video 5 Left anterior oblique view of right system angiogram showing normal dominant RCA.

\section{Learning points}

- Isolated occlusion of septal artery in coronary angiogram is rare without significant involvement of left anterior descending.

- Right bundle branch block on 12-lead ECG can be an isolated manifestation of isolated septal artery occlusion.

- Patient presenting with acute coronary syndrome with RBBB should be taken as seriously as qRBBB and substantiated with cardiac biomarkers.

Contributors All authors were involved in patient care. Article preparation was carried out by HM, corrections by SB, collection of references by SKKR and finishing touch by CNM.

Competing interests None.

Patient consent Obtained.

Provenance and peer review Not commissioned; externally peer reviewed. 


\section{REFERENCES}

1 Azuma T, Maeda $\mathrm{K}$, Akagi $\mathrm{H}$, et al. [Rest angina induced by coronary artery spasm at the first septal artery: a case report]. J Cardiol 1994;24:161-5. Japanese.

2 Tomcsanyi J, Bozsik B, Zsoldos A, et al. Isolated spontaneous septal myocardial infarction. J Electrocardiol 2012:45:280-2.
3 Furgerson JL, Sample SA, Gilman JK, et al. Complete heart block and polymorphic ventricular tachycardia complicating myocardial infarction after occlusion of the first septal perforator with coronary stenting. Cathet Cardiovasc Diagn 1998;44:434-7.

Copyright 2013 BMJ Publishing Group. All rights reserved. For permission to reuse any of this content visit http://group.bmj.com/group/rights-licensing/permissions.

BMJ Case Report Fellows may re-use this article for personal use and teaching without any further permission.

Become a Fellow of BMJ Case Reports today and you can:

- Submit as many cases as you like

- Enjoy fast sympathetic peer review and rapid publication of accepted articles

- Access all the published articles

- Re-use any of the published material for personal use and teaching without further permission

For information on Institutional Fellowships contact consortiasales@bmjgroup.com

Visit casereports.bmj.com for more articles like this and to become a Fellow 